\title{
Assessment of Malnutrition as a Risk Factor for Acute Lower Respiratory Tract Infection in Children under 5 yr Age at a Tertiary Hospital
}

\author{
Sunil Raja Manandhar, ${ }^{1}$ Peter Thorell, ${ }^{2}$ Ida Kallur, $^{2}$ Sunil Kumar Joshi ${ }^{3}$ \\ ${ }^{1}$ Department of Pediatrics, Kathmandu Medical College Teaching Hospital, Sinamangal, ${ }^{2}$ Linköping \\ University, Sweden, ${ }^{3}$ Department of Community Medicine, Kathmandu Medical College Teaching Hospital, \\ Sinamangal, Kathmandu, Nepal.
}

\begin{abstract}
Background: Malnutrition among young children is becoming a major public health concern in low income countries like Nepal where under nutrition remains one of the primary causes of ill health. Acute lower respiratory tract infection (ALRTI) and malnutrition in children are associated with morbidity and mortality in developing countries.Objective of this study was to assess ALRTI as a risk factor for malnutrition in children at Kathmandu Medical College Teaching Hospital. Methods: This was a cross-sectional study conducted at Kathmandu Medical College Teaching Hospital over 5 months duration (August - December 2017). Under 5 yrs children diagnosed as ALRTI were taken and healthy children from same age group attending the immunization clinic were the controls. Anthropometric measurements were measured and stunting and wasting were described according to the WHO classification of malnutrition. Data were analyzed using SPSS version 18. Statistical analyses were done in the form of frequency, mean and cross tabulation. Chi-Square test was used to assess the association of ALRTI with malnutrition. P value $<0.05$ was considered to be significant. Results: A total of 200 children were included in this study. Children with ALRTI $(\mathrm{n}=90)$ and controls $(n=110)$ were analyzed. Male participants were observed more in both groups $(60 \%$ and $68 \%)$. Wasting and stunting were observed more in ALRTI group than in control groups. Conclusions: This study showed there was a relation between ALRTI and malnutrition in children. So, this study has identified malnutrition as one of the major risk factor for ALRTI in under 5 yrs children.
\end{abstract}

Keywords: acute lower respiratory tract infection; malnutrition; stunting; wasting.

\section{INTRODUCTION}

Acute lower respiratory tract infection (ALRTI) is the leading cause of mortality and one of the common causes of morbidity in children under- five years of age. ${ }^{1}$ ALRTI is responsible for $19 \%$ of all deaths in children under- five years and $8.2 \%$ of all disabilities and premature mortality as measured by disability adjusted life years. ${ }^{2}$ In Nepal, ALRTI is the leading cause of childhood morbidity and mortality. ${ }^{3}$ Moreover, approximately $99 \%$ of deaths due to ALRTI takes place in the developing countries. ${ }^{4}$ It has been estimated that Nepal, India, Indonesia and Bangladesh together account for $40 \%$ of the ALRTI mortality worldwide. ${ }^{5}$

There are many known risk factors for ALRTI and malnutrition is one of them. ALRTI consists of epiglottitis, laryngitis, laryngotrachetitis, bronchitis, bronchiolitis and pneumonia ${ }^{6}$. ALRTI may have viral or bacterial aetiology. The most common pathogens causing chest infection in severely malnourished children in developing countries are Klebsiella pneumoniae, Staphylococcus aureus, Streptococcus pneumoniae, Escherichia coli and Haemophilus influenza. ${ }^{7}$

There is relative impact of various risk factors for ALRTI in children. A meta-analysis from 2013 classified the following risk factors as "definite risk factors" for ALRTI: Low birth weight (LBW), exposure to indoor air pollution, lack of exclusive breast feeding, incomplete immunization, crowding, and HIV infection. ${ }^{8}$ In addition to the definite risk factors passive smoking, male sex and history of previous acute lower respiratory tract infection risk factors were classified as "possible risk factors". 8 Other studies indicate that low socioeconomic status is also associated with a higher risk of ALRTI. ${ }^{9,10}$

Correspondence: Dr Sunil Raja Manandhar, Department of Pediatrics, Kathmandu Medical College Teaching Hospital, Sinamangal, Kathmandu, Nepal. Email: drsunilraja@gmail.com. Phone: +977-9803812218. DOI: 10.3126/ jcmsn.v15i2.21840. Article Received: 2018-11-28. Article accepted: 2019-05-28. 
Among the known risk factors for ALRTI, malnutrition might be of particular importance. It is estimated that malnutrition is associated with $50 \%$ of all deaths of under five year children on the developing countries. ${ }^{11}$ Moreover, it is also known that malnutrition by itself is a risk factor for infectious diseases and associated with an increased risk of mortality in children with ALRTI. Malnutrition among young children is becoming a major public health concern in low income countries like Nepal where under nutrition remains one of the primary causes of ill health. ${ }^{12}$ Nepal Demographic Health Survey (NDHS) 2016 highlighted under 5 yrs children are suffering from high rates of chronic malnutrition i,e 36\% were stunted and $10 \%$ were wasted. ${ }^{13}$ So, this study aims to assess role of malnutrition as a risk factor for ALRTI in children ( 3 month - 5 year of age) at Kathmandu Medical College Teaching Hospital .

\section{METHODS}

This is a cross-sectional study done at Pediatrics Department of Kathmandu Medical College Teaching Hospital (KMCTH). Admitted children of 3 months to 5 years of age diagnosed with Acute Lower Respiratory Tract Infection (ALRTI) by Consultant Pediatrician were enrolled. Healthy children of the same age group ( 3 months -5 years) attending the immunization clinic of $\mathrm{KMCTH}$ during the same period were enrolled as a control group. The study period was of 5 months duration (August - December 2017). The Ethical approval was received from Institutional Review Committee (IRC) of Kathmandu Medical College. Before enrollment of each child in this study, the parents (or other relatives) were given information about the study and written consent was taken.

Z-score specific WHO growth charts were used to assess wasting and stunting. ${ }^{14}$ The children were classified as normal if weight-for-height $\mathrm{z}$-score is Zero to $\pm 2 \mathrm{SD}$. Children are classified as moderate wasted if $z$-score was in-between -2 to $-3 \mathrm{SD}$ and severely wasted if $\mathrm{z}$-score was less than $-3 \mathrm{SD} .^{14}$ Similarly, for determining stunting, the children were classified as normal if height for age $\mathrm{z}$-score is zero to $\pm 2 \mathrm{SD}$. Children are classified as moderate stunted if $z$-score was in-between -2 to $-3 \mathrm{SD}$ and severely stunted z-score less than $-3 \mathrm{SD} .^{14}$

Anthropometric measurements were done to assess the children's nutritional status. Length/height, weight, mid-upper arm circumference (MUAC) and head circumference (HC) were measured. For child less than 2 yrs of age, length was measured by
Infantometer (Raven Equipment Limited Kiddimetre) in supine position with extended legs and the feet flexed in a right angle to the legs. For children aged $\geq 2$ yrs, height was measured by Shorr board with the children standing up straight with their back against the backboard looking straight forward. Measurements recorded as the closest $0.1 \mathrm{~cm}$. Weight was measured using SALTER electronic scale Model 914 with light clothing as possible. The children were either standing or lying on the scale which was calibrated before every measurement. The closest $0.1 \mathrm{~kg}$ was recorded. HC and MUAC was measured by cow's head brand non-stretchable plastic measuring tape which was compared to both the Infantometer and the measuring board once per month for standardization. For the measuring of MUAC, a mid of acromion process of scapula and olecronon process of ulna is taken as a midpoint of upper arm. HC was measured just above the supraorbital ridges and ears of the child after removing hat. The measurement to the closest $0.5 \mathrm{~cm}$ was recorded. These data measurements (Weight, Height, HC and MUAC) were taken by medical students' of Linköping University and procedure were supervised by senior faculty of Pediatrics and Community Medicine Departments of Kathmandu Medical College.

Data were analyzed in SPSS version 18 . Statistical analysis including proportions and mean standard deviation (SD) were calculated. Chisquare test was used a test of significance with $p$ value $<0.05$. cross tabulation was used to assess the co-relation of malnutrition with ALRTI.

\section{RESULT}

Over the period of 5 months, a total of 200 children were enrolled in this study. Among them, 90 children who were diagnosed with ALRTI and 110 were control group. Table 1 showed the demographic characteristics of children in both groups. The mean age of enrolment in ALRTI group was $16.7 \pm 12.3$ months and $12.6 \pm 5.9$ months in control group. The mean weight was $9.08 \pm 2.2$ $\mathrm{kg}$ in ALRTI group and $9.25 \pm 1.9 \mathrm{~kg}$ in control. Mean $\mathrm{HC}$ was $45.29 \pm 2.5 \mathrm{~cm}$ in the ALRTI group and $45.24 \pm 2.2 \mathrm{~cm}$ in the control group. Mean MUAC was $14.2 \pm 1.5 \mathrm{~cm}$ among the ALRTI group and $14.5 \pm 5.9 \mathrm{~cm}$ among the control group. It showed larger proportion of boys in both groups $i$. e. $54(60 \%)$ in ALRTI group and $75(68 \%)$ in the control group. Eighty three (92\%) children in the ALRTI group and $100(90 \%)$ children in the control group have completed EPI (Expanded 
Manandhar et al. Assessment of Malnutrition as a Risk Factor for Acute Lower Respiratory..

\begin{tabular}{|c|c|c|c|c|c|c|}
\hline S.N. & Variables & \multicolumn{2}{|c|}{ ALRTI $(n=90)$} & \multicolumn{2}{|c|}{ Control $(n=110)$} & p value \\
\hline 1. & Mean Age (months) & \multicolumn{2}{|c|}{$16.7 \pm 12.3(3-59)$} & \multicolumn{2}{|c|}{$12.6 \pm 5.9(3-38)$} & 0.267 \\
\hline 2. & Weight $(\mathrm{kg})$ & \multicolumn{2}{|c|}{$9.08 \pm 2.2(4-16)$} & \multicolumn{2}{|c|}{$9.25 \pm 1.9(4.8-14.7)$} & 0.068 \\
\hline 3. & Head Circumference $(\mathrm{cm})$ & \multicolumn{2}{|c|}{$45.29 \pm 2.5(38-51)$} & \multicolumn{2}{|c|}{$45.24 \pm 2.2(38-51)$} & 0.014 \\
\hline 4.. & Height $(\mathrm{cm})$ & \multicolumn{2}{|c|}{$76.78 \pm 10.9(47-106)$} & \multicolumn{2}{|c|}{$75.0 \pm 6.8(59-97)$} & 0.731 \\
\hline 5. & MUAC (cm) & \multicolumn{2}{|c|}{$14.2 \pm 1.5(10-19)$} & \multicolumn{2}{|c|}{$14.5 \pm 5.9(12-18)$} & 0.721 \\
\hline \multirow[t]{4}{*}{6.} & Gender & No. & $\%$ & No & $\%$ & p value \\
\hline & Boys & 54 & 60 & 75 & 68 & \multirow{3}{*}{0.228} \\
\hline & Girls & 36 & 40 & 35 & 32 & \\
\hline & Total & 90 & 100 & 110 & 100 & \\
\hline \multirow[t]{4}{*}{7.} & EPI shedule Immunization & No. & $\%$ & No. & $\%$ & $\mathrm{p}$ value \\
\hline & Completed & 83 & 92 & 100 & 90 & \multirow{3}{*}{0.740} \\
\hline & Not Completed & 7 & 8 & 10 & 10 & \\
\hline & Total & 90 & 100 & 110 & 100 & \\
\hline \multirow[t]{4}{*}{8.} & $\begin{array}{l}\text { Exclusive breast feeding for } 6 \\
\text { months }\end{array}$ & No & $\%$ & No & $\%$ & p value \\
\hline & Yes & 44 & 49 & 56 & 51 & \multirow{3}{*}{0.776} \\
\hline & No & 46 & 51 & 54 & 49 & \\
\hline & Total & 90 & 100 & 110 & 100 & \\
\hline
\end{tabular}

program on Immunization) schedule of Nepal. Similarly, 44(49\%) children in ALRTI group and $56(51 \%)$ in control had exclusive breast feeding for 6 months. Table 2 described the wasting and under 5 children were moderately stunted and three (6\%) children were severely stunted. Among 36 children with Bronchiolitis, three (8\%) children in each were having moderately stunted and severely

\begin{tabular}{|c|c|c|c|c|c|c|c|}
\hline \multicolumn{4}{|c|}{$\begin{array}{ll}\text { ALRTI group } & (\mathrm{n}=90)\end{array}$} & \multicolumn{4}{|c|}{$\begin{array}{ll}\text { Control group } & (\mathrm{n}=110)\end{array}$} \\
\hline SN & Height for Age & No. & $\%$ & SN & Height for Age & No & $\%$ \\
\hline 1. & Normal & 74 & 82 & 1 & Normal & 100 & 91 \\
\hline 2. & Moderately Stunted & 10 & 11 & 2 & Moderately Stunted & 10 & 9 \\
\hline \multirow[t]{2}{*}{3.} & Severely Stunted & 6 & 7 & 3 & Severely Stunted & - & - \\
\hline & Total & 90 & 100 & & Total & 110 & 100 \\
\hline S.N & Weight for Height & No. & $\%$ & SN & Weight for Height & No & $\%$ \\
\hline 1. & Normal & 71 & 79 & 1 & Normal & 98 & 90 \\
\hline 2. & Moderately Wasted & 9 & 10 & 2 & Moderately Wasted & 10 & 9 \\
\hline \multirow[t]{2}{*}{3.} & Severely Wasted & 10 & 11 & 3 & Severely Wasted & 2 & 1 \\
\hline & Total & 90 & 100 & & Total & 110 & 100 \\
\hline
\end{tabular}

stunting observed in the ALRTI and control groups. In ALRTI group, $10(11 \%)$ under 5 children were moderately stunted and six $(7 \%)$ were severely stunted whereas in control group $10(9 \%)$ children were moderately stunted only. Similarly, in ALRTI group, nine children (10\%) were moderately wasted and $10(11 \%)$ were severely wasted whereas in control group $10(9 \%)$ were moderately wasted and only two (1\%) children were severely wasted.

Figure 1 described the types of ALRTI in children. Lobar pneumonia $48(53 \%)$ was the commonest ALRTI followed by Bronchiolitis $36(40 \%)$ and Broncho pneumonia 4 (5\%) cases.

Table 3 has demonstrated co-relation of ALRTI group with respect to stunting and wasting. Among 48 children with lobar pneumonia, seven (14\%)

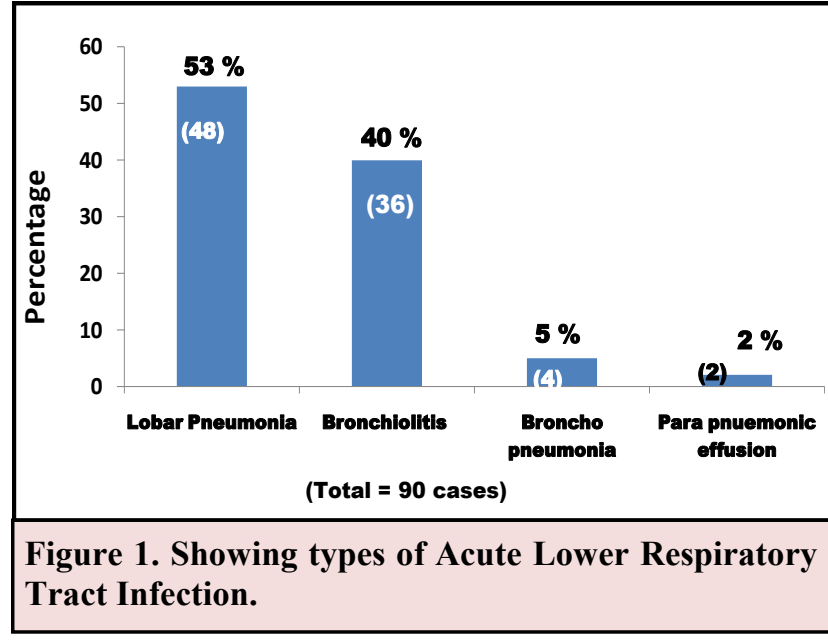

stunted respectively (p value 0.000 ). Similarly, out of 48 children with lobar pneumonia, six (12.5\%) children in each were moderately wasted and 
Manandhar et al. Assessment of Malnutrition as a Risk Factor for Acute Lower Respiratory..

\begin{tabular}{|c|c|c|c|c|c|c|c|c|c|c|}
\hline \multicolumn{11}{|c|}{ Height for Age } \\
\hline \multirow[t]{2}{*}{ S.N. } & \multirow[t]{2}{*}{ ALRTI Types } & \multicolumn{2}{|c|}{ Normal } & \multicolumn{2}{|c|}{$\begin{array}{c}\text { Moderately } \\
\text { Stunted }\end{array}$} & \multicolumn{2}{|c|}{$\begin{array}{l}\text { Severely } \\
\text { Stunted }\end{array}$} & \multicolumn{2}{|c|}{ Total } & \multirow[t]{2}{*}{$\begin{array}{c}\mathbf{p} \\
\text { value }\end{array}$} \\
\hline & & No & $\%$ & $\mathbf{N}$ & $\%$ & No & $\%$ & No & $\%$ & \\
\hline 1. & Lobar Pnuemonia & 38 & (80) & 7 & (14) & 3 & (6) & 48 & $(100)$ & \multirow{5}{*}{0.000} \\
\hline 2. & Bronchiolitis & 30 & (84) & 3 & (8) & 3 & (8) & 36 & (100) & \\
\hline 3. & Broncho pneumonia & 4 & (100) & 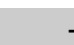 & - & - & - & 4 & (100) & \\
\hline \multirow[t]{2}{*}{4.} & Parapnuemonic effusion & 2 & $(100)$ & 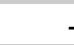 & - & - & - & 2 & $(100)$ & \\
\hline & Total & 74 & & 1 & & 6 & & 90 & $(100)$ & \\
\hline \multicolumn{11}{|c|}{ Weight for Height } \\
\hline \multirow[t]{2}{*}{ S.N. } & ALRTI Types & \multicolumn{2}{|c|}{ Normal } & \multicolumn{2}{|c|}{$\begin{array}{c}\text { Moderately } \\
\text { Wasted }\end{array}$} & \multicolumn{2}{|c|}{$\begin{array}{l}\text { Severely } \\
\text { Wasted }\end{array}$} & \multicolumn{2}{|c|}{ Total } & $\begin{array}{l}\text { p } \\
\text { value }\end{array}$ \\
\hline & & No & $\%$ & No & $\%$ & No & $\%$ & No & $\%$ & \multirow{6}{*}{0.000} \\
\hline 1. & Lobar pnuemonia & 36 & (75) & 6 & $(12.5)$ & 6 & $(12.5)$ & 48 & (100) & \\
\hline 2. & Bronchiolitis & 30 & (84) & 3 & 8 & 3 & $(8)$ & 36 & (100) & \\
\hline 3. & Broncho pneumonia & 4 & $(100)$ & - & - & - & - & 4 & $(100)$ & \\
\hline 4. & Parapnuemonic effusion & 2 & $(100)$ & - & - & - & - & 2 & $(100)$ & \\
\hline & Total & 72 & & 9 & & 9 & & 90 & (100) & \\
\hline
\end{tabular}

severely wasted respectively. whereas out of 36 children with Bronchiolitis, three $(8 \%)$ children each were having moderately wasted and severely wasted respectively ( $\mathrm{p}$ value 0.000 ).

\section{DISCUSSION}

A study done by Rijal P et al in Kathmandu found $37.7 \%$ of children with pneumonia were associated with malnutrition. ${ }^{1}$ This study described among 48 children with lobar pneumonia, $20 \%$ were stunted and $25 \%$ were wasted. Similarly, Chalabi DA in Erbil City of Iraq highlighted ALRTI was more common in children having malnutrition. The author described according to Gomez classification, $42.1 \%$ malnourished under 5 yrs children had ALRTI $(p=0.001)$ indicating malnutrition as a major risk factor for ALRTI. ${ }^{15}$ Another study done by Reddy VB et al in Chittoor district of Andhra Pradesh, India reported $38.3 \%$ under 5 yrs of age children were stunted and $18.3 \%$ were wasted and also identified among them $51.6 \%$ had ALRTI. ${ }^{16}$

Regarding nutritional status of under 5 yrs children in Ethiopia, Dadi AF et al found $48.7 \%$ were stunted and $5.8 \%$ were wasted and among these malnourished children, $19.8 \%$ had ALRTI showing co-relation of malnutrition with ALRTI. ${ }^{17}$ Out of 242 under 5 yrs children, Upadhyay RP et al found $25.2 \%$ stunted and $12.2 \%$ wasted showing high prevalence of malnutrition in under 5 years age in Pondicherry, South India. ${ }^{18}$ The study highlighted $60 \%$ of those malnourished children have ALRTI , again showing the ALRTI as the morbid condition of malnutrition in children. These findings were corroborated with our study also as according to WHO classification of malnutrition, $16(18 \%)$ were stunted and 18(20\%) were wasted with ALRTI highlighting malnutrition as a major risk factor in under 5 yrs children with ALRTI. These findings have described the burden of ALRTI in malnourished children under five year children in developing countries.

\section{CONCLUSIONS}

This study showed there was a correlation between ALRTI and malnutrition. So, this study has identified malnutrition as one of the major risk factor for ALRTI in under 5 years children.

\section{Limitation of the study}

As this study has no proper randomization, inadequate sample size and no relative risk estimation, this study has just identified malnutrition as a risk factor for ALRTI in under 5 yrs children and exact co-relation of malnutrition with ALRTI could not be assed

\section{ACKNOWLEDGEMENTS}

The authors would like to acknowledge Kathmandu Medical College and Linkoping University for promoting such type of research activity in Nepal. We would also like to give special thanks to parents and children involved in this study. At last but not the least, special thanks for Interns and Medical Officers of Pediatrics Department for helping Linkoping Students to collect data and providing communication bridge for Linkoping students and parents of the children involved in this study.

\section{Conflict of Interest: None}




\section{REFERENCES}

1. P Rijal, A Sharma, S Shrestha and S Upadhyay. Profile of acute lower respiratory tract infection in children under fourteen years of age at Nepal Medical College Teaching Hospital (NMCTH). Nepal Med Coll J 2011; 13(1): 58-61.

2. Kabra SK, Verma IC. Acute lower respiratory tract infection: The forgotten pandemic. Indian $\mathbf{J}$ Pediatr 1999; 66: 873-5.

3. Ministry of Health and Population - MOHP/ Nepal, New ERA/Nepal, and ICF International. (2012), Nepal Demographic and Health Survey 2011. Kathmandu, Nepal: MOHP/Nepal, New ERA, and ICF International. Available from: http://dhsprogram.com/pubs/pdf/FR257/ FR257.pdf.

4. Nair H, Simões EAF, Rudan I, Gessner BD, Azziz-Baumgartner E, Zhang JSF, et al. Global and regional burden of hospital admissions for severe acute lower respiratory infections in young children in 2010: A systematic analysis. Lancet. 2013;381(9875):1380-90.

5. Kumar G, Majumdar A, Kumar V, Naik B, Selvaraj K, Balajee K. Prevalence of acute respiratory infection among under-five children in urban and rural areas of Pondicherry, India. Journal of Natural Science, Biology And Medicine Jan 2015; 6(1): 3-6. Available from: Scopus ${ }^{\circledR}$.[cited March 20, 2017]

6. World Health Organization. The Management of acute respiratory infections in children : practical guidelines for outpatient care. 1995; Available from: http://www.who.int/iris/ handle/10665/41803.

7. Chisti MJ, Tebruegge M, La Vincente S, Graham SM, Duke T. Pneumonia in severely malnourished children in developing countries Mortality risk, aetiology and validity of WHO clinical signs: A systematic review. Trop Med Int Heal. 2009;14(10):1173-89.

8. Jackson S, Mathews KH, Pulanić D, Falconer R, Rudan I, Campbell H, et al. Risk factors for severe acute lower respiratory infections in children - a systematic review and meta-analysis. Croat Med J [Internet]. 2013;54(2):110-21. Available from: https://www.ncbi.nlm.nih.gov/ pmc/articles/PMC3641871.

9. Pawlinska-Chmara R, Wronka I. Assessment of the effect of socioeconomic factors on the prevalence of respiratory disorders in children. J Physiol Pharmacol. 2007;58(2, 5):523-9.
10.Amugsi DA, Aborigo RA, Oduro AR, Asoala V, Awine T, Amenga-Etego L. Socio-demographic and environmental determinants of infectious disease morbidity in children under 5 years in Ghana. Glob Health Action. 2015;8(1).

11. Rice AL, Sacco L, Hyder A, Black RE. Malnutrition as an underlying cause of childhood deaths associated with infectious diseases in developing countries. Bull World Health Organ. 2000;78(10):1207-21.

12.Paudel S Singh ,Pradhan PM, N Prasad, M Limbu, Shrestha SM, Pandeya P, Regmi B. Nutrition status of young children in periphery of Lalitpur Sub-Metropolitan city in Nepal. Journal of College of Medical Sciences-Nepal, Vol-13, No 3, July-Sept 017.

13.Population division, Ministry of Health and Population (MoHP), Government of Nepal. Nutritional status of children. In: New ERA and Macro International Inc. Nepal Demographic and Health Survey (NDHS) 2016, Kathmandu: Ministry of Health and Population, New ERA, and Macro International Inc, 2016: pp 29.

14. World Health Organization. WHO Child Growth Standards: methods and development Length/ height-for-age, weight-for-age, weight-forlength, weight-for-height and body mass indexfor-age. Acta Paediatr. 2006;95(S450).

15.Chalabi DA. Acute respiratory infection and malnutrition among children below 5 years of age in Erbil governorate, Iraq. East MediterrHealth J. 2013 Jan; 19(1):66-70.

16.Reddy VB, Kusuma YS, Pandav CS, Goswami AK, Krishnan A. Prevalence of malnutrition, diarrhea, and acute respiratory infections among under-five children of Sugali tribe of Chittoor district, Andhra Pradesh, India. J Nat Sc Biol Med 2016; 7(2):155-160.

17.Dadi AF, Kebede Y and Birhanu Z.) .Determinants of pneumonia in children aged two months to five years in urban areas of Oromia zone, Amhara region, Ethiopia. Open Access Library Journal Nov 2014; 1: e1044. http://dx.doi.org/10.4236/oalib.1101044

18.Upadhyay RP, Chinnakali P, Bhilwar M, Krishnan B, Kulkarni V, Gupta A, Rizwan SA. Prevalence of malnutrition, acute respiratory infections and diarrhoea in children aged 1-5 years in urban slums of Puducherry, South India. Int J Contemp Pediatr 2015;2:37-41.

Citation: Manandhar SR, Thorell P, Kallur I, Joshi SK. Assessment of Malnutrition as a Risk Factor for Acute Lower Respiratory Tract Infection in Children under 5 yr Age at a Tertiary Hospital. JCMS Nepal. 2019; 15(2):107-11. 